\title{
Geoguatia
} Malavsian Joumal of Societyand Space

\section{The effects of employee participation in creative-relevant process and creative self-efficacy on employee creativity}

\author{
Roshayati Abdul Hamid ${ }^{1}$, Mohd Radzuan Rahid ${ }^{1}$, Siti Ngayesah Ab Hamid ${ }^{1}$ \\ Faculty of Economics and Management, Universiti Kebangsaan Malaysia \\ Correspondence: Roshayati Abdul Hamid (email: wanrose@ukm.edu.my)
}

Received: 01 March 2020; Accepted: 15 May 2020; Published: 30 May 2020

\begin{abstract}
Employees are the key determinants of an organization's success because they possess the greatest source of the organization's creativity. To produce a highly creative thinker, employee participation in the creative-relevant process is required. However, different forms of employee participation may benefit the organization differently. Mainly, researchers agreed on three forms of participation, namely full-autonomous or discretion over individual work tasks, semi-autonomous teamwork and consultative participation. The objective of this study is to examine the relationship between the different forms of employee participation in creative-relevant process and employee creativity. In addition, creative self-efficacy has demonstrated a relationship with creativity among employees. Underpinned by the Social Cognitive Theory, this study further examined the effect of creative self-efficacy on employee creativity and as a moderator for the relationship between creative-relevant process and employee creativity. We employed a quantitative approach by distributing questionnaires to employees who are working in public/private service sectors in Malaysia and 250 employees had responded. The study hypotheses were tested using PLS structural equation modeling. The results of the study showed that there is (a) a significant relationship between full-autonomous and consultative participation in the creative-relevant process; (b) a nonsignificant relationship between semi-autonomous and creative-relevant process; (c) a significant relationship between creative-relevant process and employee creativity; (d) a significant relationship between creative self-efficacy and employee creativity, and (e) a nonsignificant moderated relationship of creative self-efficacy. This study adds to the body of knowledge on the importance of examining the different forms of employee participation and enforcing continuous training in creative-relevant process in order to develop employee creativity.
\end{abstract}

Keywords: consultative participation, creative-relevant process, creative self-efficacy, employee creativity, full-autonomous, semi-autonomous

\section{Introduction}

Given an uncertain and competitive environment in today's business, service sectors are coming to realize that their organizations' performance is depending on the employee 
creativity (Zhang \& Bartol, 2010). The process of thinking creatively can be done with the participation of employees in their daily operation and involving in the decision-making process. Researchers have pointed out that employee participation can improve the organization performance in some way and may also lead to creative thinking that triggers innovation in the organizations (Zhou, Hirst \& Shipton, 2012).

Employee participation is the process in which an employee is allowed to have control over some of their works and participates in the decision-making process (Strauss 2006), rather than just acting on orders. Employees are central to idea generation; therefore, they should be encouraged to get involved in decision making (Zubair et al., 2015). It is agreed by previous researchers that participation in decision making will affect not only worker productivity, job satisfaction, motivation, and commitment (Bhatti, Nawab \& Akbar, 2011) but also creativity (Zubair et al., 2015).

The human mind has three main potential which are intelligence, creativity, and wisdom (Sternberg, 2003). They can shape, nurture, and stimulate their mind properly and use them to think creatively and innovatively. However, in order to produce a highly creative thinker, employee participation in the creative-relevant process is required. Creative-relevant process is the process where employees are involved in the stages of problem identification, information searching and encoding, as well as ideas and alternative generation (Zhang \& Bartol, 2010). When employees put more effort to fully identify problem and gather various information to generate alternatives, the novel and useful solutions will likely to be produced. Thus, the level of their creative thinking is expanded.

The issue on lack of high-level creative thinker has been the biggest concern in almost all organizations. According to Amabile (1988), there are two types of factors influencing employees' creativity at workplace; individual and organizational factors. To develop the high-level of creative thinker, it is good to understand the role of both, the individual and the organization factors such as the level of autonomy granted to employees and their willingness to participate in a decision-making process, known as employee participation. However, the level of autonomy given depends on the different forms of employee participation which may reflected a different outcome (Gallie, 2013; Kalleberg, Nesheim \& Olsen, 2009).

Employees with high creative self-efficacy will feel confident in identifying problems and generating ideas with the skills and knowledge they own (Jiang \& Gu, 2017; Newman, Tse, Schwarz, \& Nielsen, 2018). Creative self-efficacy is defined as "the belief that one has the ability to produce creative outcomes" (Tierney \& Farmer, 2002, p. 1138). They revealed that employees' creative performance was initiated by individuals who possess creative selfefficacy. Their findings were supported by the social-cognitive theory that suggested, individuals who believed they have the ability to make things happen will be more creative. Therefore, we regard as true that creative self-efficacy is associated with greater creativity.

In summary, the different forms of employee participation may have different effect on creative-relevant process. Employees' participation in the creative-relevant process plays a significant role in developing high level creative thinkers. On the basis of previous studies and the social-cognitive theory, this study will address the following research questions; (1) to what extent do the different forms of employee participation influence creative-relevant process and the effect of creative-relevant process on employee creativity? and (2) what is the effect of creative-relevant process on employee creativity when moderated by creative selfefficacy? Hence, the purpose of this study is twofold which are to examine; (1) the different forms of employee participation in creative-relevant process and the effect of creativerelevant process on employee creativity, and (2) the effect of creative self-efficacy on employee creativity and the moderating effect of creative self-efficacy on the relationship between creative-relevant process and employee creativity. 


\section{Literature review and hypotheses development}

\section{Forms of employee participation}

Employee participation is one of the management initiatives and a process that allows employees to have some control over their work (Strauss, 2006). Employee participation is part of employee involvement as well as empowerment (Sofijanova \& Zabijakin-Chatleska, 2013). In other word, involvement is the process of employee participation in decision making, problem solving, and employees are given some autonomy to complete their work processes. Thus, employees become more productive, motivated, and committed (Sofijanova \& Zabijakin-Chatleska, 2013). Employees are given greater freedom and autonomy over their work which means empowerment and responsibility for decision making and opportunity to discuss over work issues which may influence managerial decision.

The widespread application of employee participation practices usually result in positive outcome such as quality improvement (Julien \& Tjahjono, 2009), workers' health and well-being (Knudsen, Busck \& Lind, 2011), quality of work (Gallie, 2013), organizational commitment (Bhatti et al., 2011), and creativity (Zhou, 1998). However, different forms of employee participation may benefit the organization differently. For example, a study found that participation through team is positively correlated with stress, whereas full autonomy and consultative participation are reducing the stress (Kalleberg et al., 2009). Mainly, researchers agreed on the three forms of participation namely full autonomous (individual); semi-autonomous (teamwork); and consultative participation (Gallie, 2013; Kalleberg et al., 2009; Knudsen, Busck \& Lind, 2011).

The full-autonomous is the highest degree of autonomy granted to individual employee to have control over their immediate task. This form of participation is very important to reflect how the work is organized (Gallie, 2013). Employees with full autonomous are given autonomy to design and execute their own work. As a result, they will be able to produce high-quality work and introduce possibility of self-development. In addition, they are competent to produce novel and useful alternatives in decision-making process. Semi-autonomous refers to the extent of which workers and other co-workers cooperate with each other in a relatively stable teamwork (Osterman, 2000). Based on previous studies, we believe that incorporation of teamwork in formal organization may expand more capacity for problem solving. This is because more ideas could be generated from a group of employees in a team. However, poor coordination in teamwork will affect cooperation among team members.

Consultative participation allows employees to deploy influence over some organizational work-related issues (Kalleberg et al., 2009). Consultative participation refers to practices where management encourages their employees to give opinions or suggestions relating to work, but the final decisions still fall under management jurisdiction. Examples of consultative participation include suggestion plans, regular meetings with management (Bhatti et al., 2011), and problem-solving groups such as quality circles (Gallie, 2013).

\section{Different forms of employee participation in creative-relevant process}

Managements encouraged and developed creativity among employees (Shalley \& Gilson, 2004) in order for their organization to be more innovative and effective (Shalley, Zhou \& Oldman, 2004). Previous literature agreed that participation and autonomy in decision making are among the vital predictors for creative outcomes (Amabile, Schatzel, Moneta \& Kramer, 2004; Zubair et al., 2015) and they are the potential source of creativity (Zhou et al. 2012). Creativity can be defined as "the production of novel and useful ideas for problem 
solving and meeting the organization goal" (Amabile, 2012). Employee creativity is not just providing useful outcomes but also incorporating the development of new and practical solutions pertaining to workplace issues (Amabile, 1983).

Employees need to participate in the creativity process that gradually leads to creative outcome, namely creative-relevant process. However, the degree of employee participation in the process varies (Zhang \& Bartol, 2010). When individuals pay little attention to their work, they will minimally participate in the workplace problem and may not found any creative or useful solution to the problem that have occurred. On the other hand, individuals that devote all their attention to work are most likely to be involved in the workplace problems they encounter (Gallie, 2013). Thus, when an individual dedicates substantial attention to a workplace problem, creative solutions will be generated and it will also lead to their participation in the creative-relevant process (Zhang \& Bartol, 2010).

It is clear from the literature review that employee participation in creative-relevant process will contribute to employee creativity. However, to which extent the different forms of employee participation will contribute to the higher level of employee creativity is still open for discussion. So, for this study, 'creativity' is used to describe an outcome which refers to the extension of novel and useful ideas production and 'creative-relevant process' is the process of which creativity occurs. The activities involved in the creative process are problem identification, information searching, and idea generation (Amabile, 1983; Zhang \& Bartol, 2010).

H1a: There is a significant relationship between full-autonomous (individual) and creativerelevant process.

H1b: There is a significant relationship between semi-autonomous (teamwork) and creative- relevant process.

H1c: There is a significant relationship between consultative participation and creativerelevant process.

\section{Creative-relevant process and employee creativity}

The literature on creativity offered a few ways to look at the concept of creativity. Amabile (1997) defined creativity as "...simply the production of novel, appropriate ideas in any realm of human activity, from science, to the arts, to education, to business, to everyday life. The ideas must be novel, different from what's been done before; they must be appropriate to the problem or opportunity presented (Amabile, 1997:40)". Creativity is a collection of ideas, either creating something new or using old ideas in a new way (Maley, 2003) and creativity means to do something in a way that is not normally done when the normal way does not work out (Simonton, 2017). Thus, creativity is not just "thinking outside the box" but finding new ways of doing things that provide added value in solving problems or seizing opportunity.

Previous research recommended many factors that may enhance employee creativity (Shalley et al., 2004) including motivation, empowerment, and employees' abilities (Aslam, 2017). In addition, some researchers found that employees who participate in the creativerelevant process will improve their creativity, too (Aslam, 2017; Zhang \& Bartol, 2010). There are three stages in creative-relevant process. The stages in creative-relevant process are similar to decision making process, only that it emphasized more on creative idea generation. The preliminary stage is problem identification where employees have to understand the nature of the problem, gather some information from various perspective and break down the difficult problem into parts to get more understanding. The second stage is information searching where employees need to search variety information from multiple source to 
initiate thinking and to be utilized for the outcome. Finally, the third stage is idea generation. Employees will generate new ideas to solve the problem using diverse sources of information and come out with a significant number of alternatives (Reiter-Palmon \& Illies, 2004; Zhang \& Bartol, 2010).

Creative-relevant process plays a significant role in influencing employee's creativity (Aslam, 2017; Zhang \& Bartol, 2010). Thus, creative outcomes will be generated when employees devote substantial attention and put more effort to identify the problem, get more information, and generate alternatives and various ideas to produce novel and useful solutions. In other words, employees need to participate in the creative-relevant process so that they are able to generate the creative outcome.

$\mathrm{H} 2$ : There is a significant relationship between creative-relevant process and employee creativity.

\section{Moderating Effect of Creative Self-efficacy and Employee Creativity}

Social-cognitive theory by Bandura (1997) introduced the term 'self-efficacy' which explained about individuals' belief on their ability to organize and execute what they want under a variety of circumstances. Self-efficacy is the key determinants whether an individual can successfully make things happen through their own action in the way they want (Bandura, 2001). The individual effort is more persistent if they believed in their capabilities (Bandura, 1989). Therefore, individuals with high confidence level in their capabilities are likely to accept difficult tasks as a challenge (Ridzwan \& Mohamed, 2016). In addition, it will boost up their level of motivation and put more effort to face the challenges (Bandura, 1989).

Tierney and Farmer (2002) coined the concept of creative self-efficacy as a process similar to that deployed for self-efficacy. They believe that individuals with creative selfefficacy will produce creative outcomes (Tierney \& Farmer, 2002). Empirical studies have shown that creative self-efficacy is related to idea generation (Tierney \& Farmer, 2002) and creative performance (Gong, Huang \& Farh, 2009; Haase et al., 2018). Individuals who have confidence in their own ability will have high creative self-efficacy and may perform high degree of creativity (Malik, Butt \& Choi, 2015) and will approach problem solving in an innovative way.

We base this view on previous research that have shown that employees are more creative when they possess higher level of creative self-efficacy (Carmeli \& Schaubroeck, 2007; Tierney \& Farmer, 2002). Even though there was a study that examined the mediating role of employee creative self-efficacy between employee learning orientation and employee creativity (Gong et al. 2009), we feel that creative self-efficacy is also best suited as moderator. The reason being, we want to examine when and not why the above relationship is stronger. In this study, the moderating effect of creative self-efficacy will be on the relationship between creative-relevant process and employee creativity.

Thus, we expect that the degree of employee creativity would vary depending on employee's creative self-efficacy. Normally, individuals with low creative self-efficacy will pay little attention to improving their routine task and will engage minimally in problem solving which leads to less creative solution.

H3: There is a significant relationship between creative self-efficacy and employee creativity. 
H4: Creative self-efficacy will moderate the relationship between creative-relevant process and employee creativity such that the relationship is stronger for those with high rather than low creative self-efficacy.

\section{Research framework}

Drawing from the above hypotheses, we illustrate the research framework to explain (i) the direct relationship between the different forms of employee participation and creativerelevant process, (ii) the direct relationship between creative-relevant process and employee creativity and (iii) the moderating effect of creative self-efficacy. Figure 1 illustrate the research framework.

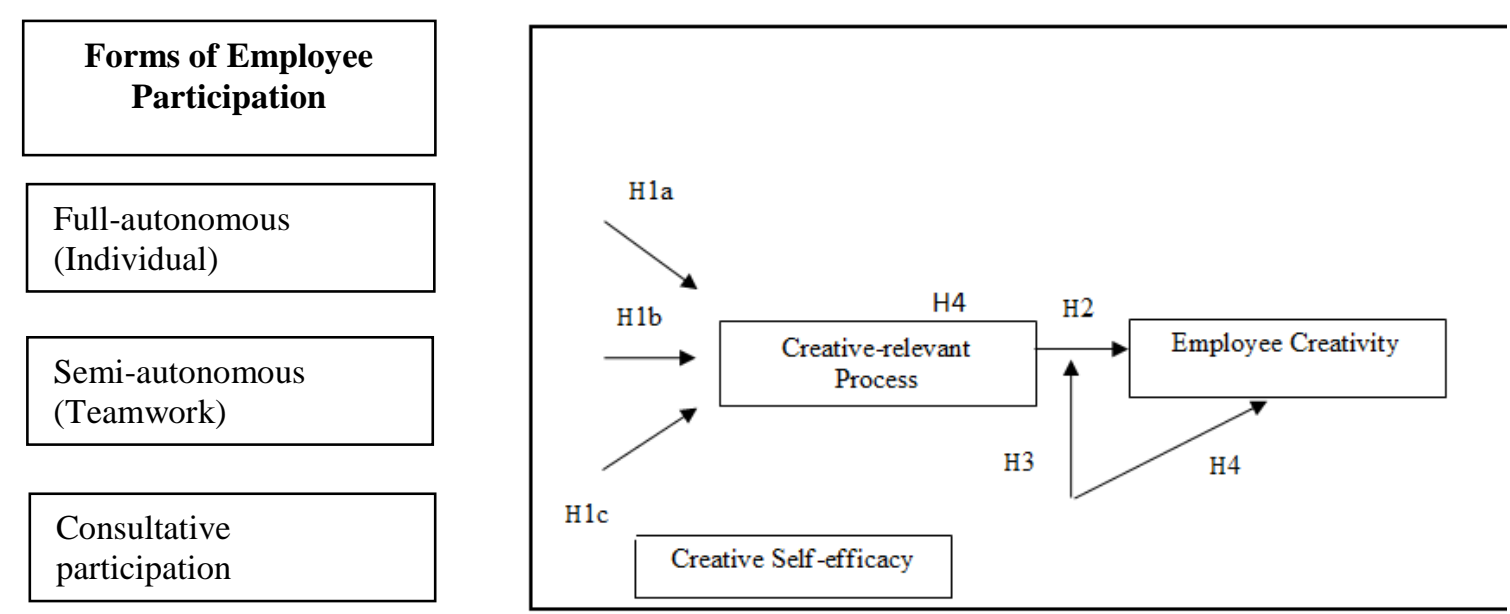

Figure 1. Research framework for the relationship between different forms of employee participation, creative-relevant process and employee creativity - moderated by creative self-efficacy.

\section{Method}

The study was conducted using quantitative study approach and cross-sectional among employees working in a public/private service organization. Initially, this study proposed public service sector (government agency) because little is known about the new public management in relation to creativity. However, due the low response rate from employees of public service sector, this study decided to collect data from private sector. Regardless of public or private service sector, all employees are required to be creative in their routine task such as to adapt with the technological changes, to do continuous improvement, and to create lean frontline services.

Self-reported questionnaire was distributed to obtain responses from the participants. This method is appropriate because the constructs used in this study referred to respondent own perceptions. The questionnaires were handed over to an appointed person-in-charge to be distributed to the employees of the organization. After a week, the completed questionnaires were collected. This study used a convenience sampling because the name list of all employees in the organization were not easily accessible. Partial least squares structural equation modelling (PLS-SEM) with SmartPLS 3.0 (Ringle, Wende \& Becker, 2015) was used to test the hypotheses.

The survey questionnaire was developed by adapting previous validated measurement scales. Different forms of employee participation were measured using Gallie (2013). 
Respondents were asked series of questions such as "How much influence do you personally have on deciding how you are to do the task?" and "How much you can express your views in the issues of training and career development". Respondents indicated the frequency of their participation in daily task and decision-making process on a five-point Likert-type scale ranging from 1 (none at all) to 5 (a great deal). To measure the creative-relevant process, an 11 items scale was used for this study adapted from Amabile (1983) and Reiter-Palmon and Illies (2004). Respondents answered on a five-point scale ranging from (1) never to (5) very frequently. "I think about the problem from multiple perspective" and "I generate a significant number of alternatives to the same problem before I choose the final solution" are representative items.

To assess employee perceived for creative self-efficacy, we adapted the New General Self-Efficacy Scale by Chen, Gully, and Eden (2001) in the context of creativity. Using fivepoint rating scale respondents showed how much they agreed or disagree by answering eight statements. A sample item was "I will be able to achieve most of the goals that I have set for myself in a creative way". Finally, the employee creative thinking was measured using a 13item creativity scale adapted from Zhou and George (2001). Respondents answered on fivepoint scale ranging from 1 (not at all characteristics) to 5 (very characteristics) which was adopted from the same source. Additional instruction was given to respondents, i.e. "Please rate your characteristic based on each of the behaviors in the following questions". The sample items are "I am someone who is not afraid to take risks" and "I am someone who comes up with creative solutions to problems".

\section{Findings}

\section{Results}

Eventually 250 questionnaires were return from the survey. Of these numbers, only 247 cases were usable for further analyses. Out of the useable sample, majority of the respondents were $(61 \%)$, Malays $(87 \%)$ and married (60\%). The mean age was 35 years (range $21-60$ years). Sixty six percent (66\%) of the respondents completed up to the secondary school and $34 \%$ completed higher education. The respondents' average tenure in their organization was 8 years. Majority of the respondents occupied the non-executive positions (60\%).

Six constructs were used in this study, which are full-autonomous, semi-autonomous, consultative participation, creative-relevant process, creative self-efficacy and employee creativity. The indicator reliability of the measurement model was accepted as the indicator loadings for each construct shows 0.70 and above. The summary of internal consistency reliability results is shown in Table 1 . The internal consistency reliability of the constructs is well above the cut-off value of 0.70 . Cronbach's alpha values also show good reliability, ranging from 0.742 to 0.964. All AVE values are above 0.50, with the lowest AVE value of 0.568 for full-autonomous indicating that more than half of the respective indicators' variance was explained by its latent variable. Therefore, convergent validity is established in this study.

Table 1: Constructs, internal consistency reliability, and average variance extracted

\begin{tabular}{lccc}
\hline Construct & Cronbach's Alpha & Composite Reliability & AVE \\
\hline Full-autonomous & 0.742 & 0.839 & 0.568 \\
Semi-autonomous & 0.865 & 0.908 & 0.712 \\
Consultative & 0.892 & 0.918 & 0.651
\end{tabular}




$\begin{array}{llll}\text { Creative-relevant } & 0.936 & 0.945 & 0.612 \\ \text { Creative self-efficacy } & 0.956 & 0.963 & 0.763 \\ \text { Employee Creativity } & 0.964 & 0.968 & 0.701\end{array}$

Having established a valid and reliable measurement model, this study continued with structural model assessment. Table 2 shows the path coefficient, $t$-value and $p$-value for the hypotheses relationship. The results for first direct relationships between the three forms of employee participation and creative-relevant process shows that two of three forms of participation are significant. Specifically, the path coefficient was statistically significant for the relationship between full-autonomous, consultative participation and creative-relevant process $(\beta=0.279, \mathrm{p}<0.000 ; \beta=0.182, \mathrm{p}=0.008)$ respectively. Therefore, Hypotheses 1a and 1c stating that there is a relationship between full-autonomous, consultative participation and creative-relevant process were supported. On the other hand, hypothesis $1 \mathrm{~b}$ stating that there is a relationship between semi-autonomous and creative-relevant process was not supported $(\beta=0.077, \mathrm{p}=0.308)$.

Hypothesis 2 and hypothesis 3 specify the direct effects among creative-relevant process, creative self-efficacy and employee creativity. Results from the PLS-SEM analysis support both hypothesized relationships. That is, there is a direct positive relationship between creative-relevant process and employee creativity $(\beta=0.192, p=0.008)$, and there is a direct relationship between creative self-efficacy and employee creativity $(\beta=0.612, p<$ 0.000). Therefore, hypothesis 2 and hypothesis 3 were supported.

Finally, Hypothesis 4 proposed that creative self-efficacy will moderate the relationship between creative-relevant process and employee creativity. The results of the bootstrapping procedure showed that the path coefficient between the interaction variable and employee creativity was not statistically significant $(\beta=0.020, \mathrm{p}=0.550)$. Therefore, Hypothesis 4 was not supported.

Table 2: Hypotheses testing results

\begin{tabular}{lcccc}
\hline $\begin{array}{l}\text { Hypotheses } \\
\text { Relationship }\end{array}$ & $\begin{array}{c}\text { Path } \\
\text { Coefficient }\end{array}$ & $\boldsymbol{t}$-value & $\boldsymbol{p}$-value & Result \\
\hline H1a: FA $\rightarrow$ CRP & 0.279 & 4.409 & 0.000 & Supported \\
H1b: SA $\rightarrow$ CRP & 0.077 & 1.020 & 0.308 & Not supported \\
H1c: CP $\rightarrow$ CRP & 0.182 & 2.622 & 0.008 & Supported \\
H2: CRP $\rightarrow$ EC & 0.192 & 2.646 & 0.008 & Supported \\
H3: CSE $\rightarrow$ EC & 0.612 & 8.265 & 0.000 & Supported \\
H4: CRPxCSE $\rightarrow$ EC & 0.020 & 0.598 & 0.550 & Not supported \\
\hline
\end{tabular}

Note: $\mathrm{FA}=$ Full Autonomous, $\mathrm{SA}=$ Semi-Autonomous, $\mathrm{CP}=$ Consultative Participation, $\mathrm{CRP}=\mathrm{Creative-relevant}$ Process, CSE=Creative Self-efficacy, EC=Employee Creativity

The coefficient of determination, $R^{2}$ for the first direct relationship between the three forms of employee participations and creative-relevant process is 0.172 , which indicates that $17.2 \%$ of the variance in creative-relevant process construct is explained by the predictors of the model. The coefficient of determination, $R^{2}$ also show that the research model explained $53.5 \%$ variation in the employee creativity construct. Thus, this model explained that the predictor variables moderately well (Henseler et al., 2009). 


\section{Discussion and Conclusion}

In general, this study examined two main effect models; first, to examine the direct relationship between three different forms of employee participation with creative-relevant process, and second, to examine the direct relationship between creative-relevant process with employee creativity. In addition, the later model also examined the moderation effect of creative self-efficacy. Initially, we intend to examine the creative-relevant process as a mediator for the relationship between the three forms of employee participation and employee creativity. However, the result of this study did not meet one of the mediation requirements. According to Baron and Kenny (1986), if the mediator is not associated with the independent variable, then it could not mediate anything.

As expected, the result of this study showed that the different forms of employee participation affected the creative-relevant process at a different level. Out of the three forms of employee participation, only two were supported. There is a positive relationship between full-autonomous and consultative participation with creative-relevant process, whereby fullautonomous most strongly associated with creative-relevant process. On the other hand, this study found that semi-autonomous was not significantly effective in creative-relevant process. These findings were consistent with Gallie (2013) that specified among the three forms of employee participation, the strongest and significantly associated with quality of work are full-autonomous and consultative participation rather than semi-autonomous.

Result revealed that semi-autonomous participation through teamwork had the weakest effects out of the three forms of employee participation. We strongly believe that the non-significant result is caused by the loose coordination and less cooperation among team members. Poor coordination in teamwork caused team members to feel frustrated especially when they detected some members contributed less than others (Colquitt, Lepine \& Wesson, 2019). Lack of coordination created motivational loss and dissatisfaction among team members. Those feelings reduced cooperation, and in turn, exert less effort when working on team tasks such as participated in creative-relevant process.

This study also found that there is a significant direct positive relationship between creative-relevant process and employee creativity. According to Zhang and Bartol (2010) and Aslam (2017), creative-relevant process is crucial in explaining employee creative outcomes. For a creative response to emerge, employees need to engage in creative-relevant process activities (Amabile, 1983; Reiter-Palmon \& Illies, 2004). These processes will explore the employees' cognitive pathways to be more flexible in finding a solution in a creative way. Therefore, the finding of this study supports previous research on the importance of creativerelevant process.

However, the moderating role of creative self-efficacy on the relationship between creative-relevant process and employee creativity was not supported. Essentially, both high and low creative self-efficacy did not strengthen or weaken the relationship between creativerelevant process and employee creativity. There are a few plausible reasons that may explain the absence of a moderating effect of creative self-efficacy. The non-significant result could be due to theoretical perspective which includes the low power of the sample size. However, the results of the non-significant regression analysis did not mean that there was no moderation effect in the study sample. This may be due to insufficient evidence in the data set (Hair et al., 2006).

Another plausible reason is the demographic background of the respondents. Perception of creative self-efficacy is differed for each individual. Majority of the respondents in this study hold the non-executive positions $(60 \%)$ and completed up to the secondary level (66\%). Therefore, we believe that this category of employees perceives both creative-relevant process and creative self-efficacy as independently functioning. This means 
that if the employees are involved in the creative-relevant process, they are confident about their ability and it may not be necessary to have a creative self-efficacy. On top of that, creative self-efficacy can be developed through training. However, in most organizations the training on self-efficacy is mainly provided to the executive level because these levels have more empowerment in decision making.

Creative-relevant process is a cognitive activity which include explicit and implicit knowledge to understand the complexities of the problem and create a novel and useful solution during problem solving. Therefore, we assumed that creative-relevant process can act independently in influencing employee creativity. Although creative self-efficacy did not play a role as a moderator, the direct relationship between creative self-efficacy and employee creativity was significantly related. The significant relationship was supported and consistent with previous study (Tierney \& Farmer, 2002).

A number of theoretical implications can be drawn from the findings of this study. First, this study adds to the body of knowledge on how the different forms of employee participation influenced the creative-relevant process. Consistent with previous study, the different forms of employee participation will benefit the organization differently. Second, this study specifically contributes to the creativity literature by demonstrating the importance of creative-relevant process in explaining employee creativity. Finally, although the moderating effect of creative self-efficacy was not supported, but the present study agreed with social-cognitive theory that creative self-efficacy will produce creative outcome. This is proven when result showed there was a significant relationship between creative self-efficacy and employee creativity.

Organizations nowadays are looking for the employees with higher level of creative thinking to foster innovation in their organizations. Thus, the findings may provide some practical insights for organizations to enhance the employee creativity. The level of autonomy given to employee and their willingness to take an active role in decision making will give a great impact to the development of employee creative thinking. Therefore, in order to encourage employee creativity, manager should increase more autonomy and empowerment to their employees. Furthermore, managers need to motivate their employees to participate in creative-relevant process by providing continuous training. Organization must give full support and encouragement for employee to develop their own creative selfefficacy which able to foster organizations' innovation.

However, there are some limitation that might indicate an interesting direction for future study. First, this study proceeds to examine two main direct relationship without the mediating effect of creative-relevant process. This due to due to one of the results did not meet the requirement for mediator (as explained in discussion section). Therefore, future research should consider using full-autonomous to test the creative-relevant process as a mediator since this form of employee participation have the strongest associated with creative-relevant process. Second, the moderating effect in this study was not significant which suggested the presence of other variables such as psychological climate or psychological capital. In addition, majority of the respondents in this study were nonexecutive level which might cause the non-significant finding for the moderating effect. Therefore, future research may consider focusing on the executive level respondents.

In conclusion, this study examined whether the different forms of employee participation will benefit creative-relevant process differently. Our study enhanced the research framework by examining the direct relationships of creative-relevant process, creative self-efficacy and employee creativity. Next, we examined the moderating effect of creative self-efficacy on the relationship between creative-relevant process and employee participation. Our findings suggested that full-autonomous and consultative participation yielded a stronger commitment in creative-relevant process compared to semi-autonomous 
participation. In addition, employees participating in creative-relevant process and employees' creative self-efficacy are crucial in developing employee creativity.

\section{Acknowledgements}

The first author would like to thank the Malaysian Ministry of Higher Education and Universiti Kebangsaan Malaysia (National University of Malaysia) for the resources and support (FRGS Grant: FRGS/2/2014/SS05/UKM/03/2) needed to complete this study.

\section{References}

Amabile, T.M. (1983). The social psychology of creativity: A componential conceptualization. Journal of Personality and Social Psychology, 45, 357-376.

Amabile, T.M. (1997). Motivating creativity in organizations: On doing what you love and loving what you do. California Management Review, 40, 39-58.

Amabile, T.M. (2012). Componential Theory of Creativity. Working Paper 12-096.

Amabile, T.M., Schatzel, E.A., Moneta, G.B., \& Kramer, S.J. (2004). Leader behaviors and the work environment for creativity: Perceived leader support. Leadership Quarterly, $15,5-32$.

Aslam, S. (2017). Psychological empowerment on creativity among employees of IT sector: The mediating role of creative process, engagement and intrinsic motivation. Canadian Social Science, 13(6), 11-34.

Bandura, A. (1989). Human agency in social cognitive theory. American Psychologist, 44, $1175-1184$.

Bandura, A. (1997). Self-efficacy: The exercise of control. New York: Freeman.

Bandura, A. (2001). Social cognitive theory: An agentic perspective. Annual Review of Psychology, 52, 1-26.

Baron, R. M., \& Kenny, D.A. (1986). The moderator-mediator variable distinction in social psychological research: Conceptual, strategic, and statistical considerations. Journal of Personality \& Social Psychology, 51, 1173-1182.

Bhatti, K.K., Nawab, S., \& Akbar, A. (2011). Effect of Direct Participation on Organizational Commitment. International Journal of Business and Social Science, 2(9), 15-23.

Carmeli, A., \& Schaubroeck, J. (2007). The influence of leaders' and other referents' normative expectations on individual involvement in creative work. The Leadership Quarterly, 18(1), 35-48.

Chen, G., Gully, S.M., \& Eden, D. (2001). Validation of a new general self-efficacy scale. Organizational Research Methods, 4, 62-83.

Colquitt, J.A., Lepine, J.A. \& Wesson, M.J. (2019). Organizational Behavior. Improving Performance and Commitment in The Workplace, International Edition, $\left(6^{\text {th }} \mathrm{ed}\right)$. McGraw-Hill Irwin.

Gallie, D. (2013). Direct Participation and the Quality of Work. Human Relations, 66(4), 453-473.

Gong, Y., Huang, J., \& Farh, J. (2009). Employee learning orientation, transformational leadership, and employee creativity: The mediating role of employee creative selfefficacy. Academy of Management Journal, 52, 765-778.

Haase, J., Hoff, E., Hanel, P., \& Innes-Ker, А. (2018). A meta-analysis of the relation between creative self-efficacy and different creativity measurements. Creativity Research Journal 30, 1-16 
Hair, J.F., Black, W.C., Babin, B.J., Anderson, R.E., \& Tatham, R.L. (2006). Multivariate

Data Analysis, (6 ${ }^{\text {th }}$ ed). Upper Saddle River, NJ: Pearson Prentice Hall.

Henseler, J., Ringle, C.M. \& Sinkovics, R.R. (2009). The use of partial least squares path modeling in international marketing. In R., Sinkovics, \& P.N., Ghauri. (eds.) Advances in International Marketing. 277-320.

Jiang, W., \& Gu, Q. (2017). Leader creativity expectations motivate employee creativity: A moderated mediation examination. International Journal Human Resource Management, 28, 724-749

Julien, D.M., \& Tjahjono, B. (2009). Lean Thinking Implementation at a Safari Park. Business Process Management, 15, 321-335.

Kalleberg, A.L., Nesheim, T. \& Olsen, K.M. (2009). Is participation Good or Bad for Workers? Effects of Autonomy, Consultation and Teamwork on Stress Among Workers in Norway. Acta Sociologica, 52, 99-116.

Knudsen, H., Busck, O., \& Lind, J. (2011). Work Environment Quality: The Role of Workplace Participation and Democracy. Work, Employment and Society, 25, 379-396.

Maley, A. (2003). Creative approaches to writing materials. In B., Tomlinson (Ed.), Developing materials for language teaching (pp. 183-198). Cambridge: Cambridge University Press.

Malik, M.A.R., Butt, A.N., \& Choi, J.N. (2015). Rewards and Employee Creative Performance: Moderating Effects of Creative Self-efficacy, Reward Importance, and Locus of Control, Journal of Organizational Behavior 36, 59-74.

Newman, A., Tse, H.H.M., Schwarz, G., \& Nielsen, I. (2018). The effects of employees' creative self-efficacy on innovative behavior: The role of entrepreneurial leadership. Journal of Business Research, 89, 1-9.

Osterman, P. (2000). Work Reorganization in an Era of Restructuring: Trends in Diffusion and Effects on Employee Welfare. Industrial and Labor Relations Review, 53, 179-196.

Reiter-Palmon, R., \& Illies, J.J. (2004). Leadership and creativity: Understanding leadership from a creative problem-solving perspective. Leadership Quarterly, 15, 55-77.

Ridzwan Che' Rus \& Mohamed Nor Azhari Azman (2016) Pengaruh minat terhadap pembentukan pekerja berkemahiran di Malaysia: Kajian kes pelatih Institut Latihan Perindustrian Kuala Lumpur (ILPKL). Geografia-Online Malaysian Journal of Society and Space, 12(3), 168 - 180.

Ringle, C.M., Wende, S. \& Becker, J.M. (2015). SmartPLS (Version 3: Software). Available from http://www.smartpls.com

Shalley, C.E., \& Gilson, L.L. (2004). What leaders need to know: A review of social and contextual factors that can foster or hinder creativity? Leadership Quarterly, 15, 3353.

Shalley, C.E., Zhou, J., \& Oldman, G.R. (2004). The effects of personal and contextual characteristics on creativity: Where should we go from here? Journal of Management, 30, 933-958.

Simonton, D.K. (2017). Defining creativity: Don't we also need to define what is not creative? Journal of Creative Behavior, 51, 281-284

Sofijanova, E. \& Zabijakin-Chatleska, V. (2013) Employee involvement and organizational performance: Evidence from the manufacturing sector in Republic of Macedonia. Trakia Journal of Sciences, 11(1), 31-36.

Sternberg, R.J. (2003). Wisdom, intelligence, and creativity synthesized. New York: Cambridge University Press.

Strauss, G. (2006). Worker participation-some under-considered issues. A Journal of Economy and Society, 45(4), 778-803. 
Tierney, P., \& Farmer, S.M. (2002). Creative self-efficacy: Potential antecedents and relationship to creative performance. Academy of Management Journal, 45, 11371148.

Zhang, X., \& Bartol, K.M. (2010). Linking empowering leadership and employee creativity: The influence of psychological empowerment, intrinsic motivation, and creative process engagement. Academy of Management Journal, 53(1), 107-128.

Zhou, J. (1998). Feedback valence, feedback style, task autonomy, and achievement orientation: Interactive effects on creative performance. Journal of Applied Psychology, 83, 261-276.

Zhou, J., \& George, J.M. (2001). When job dissatisfaction leads to creativity: encouraging the expression of voice. Journal of Applied Psychology, 44, 682-96.

Zhou, Q., Hirst, G., \& Shipton, H. (2012). Context matters: Combined influence of participation and intellectual stimulation on the promotion focus-employee creativity relationship. Journal of Organizational Behavior, 33, 894-909.

Zubair, A., Bashir, M., Abrar, M., Baig, S.A., \& Hassan, S.Y. (2015). Employee's participation in decision making and manager's encouragement of creativity: The mediating role of climate for creativity and change. Journal of Service Science and Management, 8, 306-321. 